\title{
A randomized double blind control trial comparing filgrastim and pegfilgrastim in cyclophosphamide peripheral blood hematopoietic stem cell mobilization
}

\author{
Jew-Win Kuan ${ }^{\text {a,* }}$, Anselm-Ting Su ${ }^{\text {b }}$, Shu-Ping Wong ${ }^{c}$, Xavier Yoon-Han Sim ${ }^{\text {a,d }}$, \\ See-Guan Toh a,d, Tee-Chuan Ong a,d, Jay-Suria Rajasuriarr a,d, Su-Hong Lim ${ }^{\text {a,d }}$, \\ Yong-Khee Guan a,d, Hong-Keng Liew ${ }^{\mathrm{a}, \mathrm{d}}$, Pek-Kuen Liew ${ }^{\mathrm{a}, \mathrm{d}}$, \\ Jerome Tsen-Chuen Tan a,d, Ahlam-Naila Kori a,d, Yuin-Yin Cheng a,d, \\ Sen-Mui Tan a,d, Kian-Meng Chang a,d \\ a Department of Medicine, Faculty of Medicine and Health Sciences, Universiti Malaysia Sarawak, Sarawak, Malaysia \\ ${ }^{\mathrm{b}}$ Department of Community Medicine and Public Health, Faculty of Medicine and Health Sciences, Universiti Malaysia Sarawak, Sarawak, \\ Malaysia \\ ${ }^{\mathrm{c}}$ Department of Pharmacy, Ampang Hospital, Selangor, Malaysia \\ ${ }^{\mathrm{d}}$ Department of Hematology, Ampang Hospital, Selangor, Malaysia
}

\section{A R T I C L E I N F O}

\section{Article history:}

Received 5 June 2014

Received in revised form 18 March 2015

Accepted 23 March 2015

\section{Keywords:}

Hematopoietic stem cell mobilization Pegfilgrastim

Granulocyte colony-stimulating factor Filgrastim

\begin{abstract}
A B S T R A C T
There are few randomized trials comparing filgrastim and pegfilgrastim in peripheral blood stem cell mobilization (PBSCM). None of the trials studied the effects of the timing of pegfilgrastim administration on the outcomes of mobilization. We conducted a randomized triple blind control trial comparing the outcomes of filgrastim $5 \mu \mathrm{g} / \mathrm{kg}$ daily from day 3 onwards, 'early' pegfilgrastim $6 \mathrm{mg}$ on day 3 and 'delayed' pegfilgrastim $6 \mathrm{mg}$ on day 7 in cyclophosphamide PBSCM in patients with no previous history of mobilization. Peripheral blood (PB) CD34+ cell count was checked on day 8 and day 11 onward. Apheresis was started when $\mathrm{PB} C D 34+\geq 10 / \mu \mathrm{l}$ from day 11 onward. The primary outcome was the successful mobilization rate, defined as cumulative collection of $\geq 2 \times 10^{6} / \mathrm{kg}$ CD34+ cells in three or less apheresis. The secondary outcomes were the day of neutrophil and platelet engraftment post transplantation. There were 156 patients randomized and 134 patients' data analyzed. Pegfilgrastim $6 \mathrm{mg}$ day 7 produced highest percentage of successful mobilization, 34 out of 48 (70.8\%) analyzed patients, followed by daily filgrastim, 28 out of $44(63.6 \%)$ and day 3 pegfilgrastim, 20 out of $42(47.6 \%)(p=0.075)$. Pegfilgrastim day 7 and daily filgrastim reported $1.48(\mathrm{p}=0.014)$ and $1.49(\mathrm{p}=0.013)$ times higher successful mobilization rate respectively as compared to pegfilgrastim day 3 after adjusting for disease, gender and exposure to myelotoxic agent. Multiple myeloma patients were three times more likely to achieve successful mobilization as compared to acute leukemia or lymphoma patients. Pegfilgrastim avoided the overshoot of white cells compared to filgrastim. There was no difference in the duration of both white cells and platelet recovery post transplantation between the three interventional arms.
\end{abstract}

(c) 2015 Elsevier Ltd. All rights reserved.

This trial was registered with National Medical Research Registry as NMRR-10-755-6906.

* Corresponding author. Department of Medicine, Faculty of Medicine and Health Sciences, Universiti Malaysia Sarawak (UNIMAS), 94300 Kota Samarahan, Sarawak, MALAYSIA. Tel.: + 6082581000 / 581388, ext 5361; fax: + 60826650152.

E-mail address: kuanjewwin@gmail.com (J.-W. Kuan). 